\title{
Serum-Free Suspension Adaptation of HEK-293T Cells: Basis for Large-Scale Biopharmaceutical Production
}

\author{
Ana Luiza Oliveira Lomba ${ }^{1}$ \\ https://orcid.org/0000-0001-5972-9232 \\ Mariane Cariati Tirapelle ${ }^{2}$ \\ https://orcid.org/0000-0002-8358-6873 \\ Rafael Tagé Biaggio' \\ https://orcid.org/0000-0001-6805-7714 \\ Mário Soares Abreu-Neto ${ }^{1}$ \\ https://orcid.org/0000-0002-9834-7832
}

\author{
Dimas Tadeu Covas ${ }^{1}$ \\ https://orcid.org/0000-0002-7364-2595 \\ Virginia Picanço-Castro ${ }^{1}$ \\ https://orcid.org/0000-0001-8474-4610
}

\author{
Kamilla Swiech ${ }^{1,2}$ \\ https://orcid.org/0000-0002-4811-9751
}

Amanda Mizukami*

https://orcid.org/0000-0003-2149-0101

\begin{abstract}
1 University of São Paulo, Ribeirão Preto Medical School, Center for Cell-based Therapy, Regional Blood Center of Ribeirão Preto, Ribeirão Preto, Sāo Paulo, Brazil; 2University of São Paulo, School of Pharmaceutical Sciences of Ribeirão Preto, Department of Pharmaceutical Sciences, Ribeirão Preto, Sāo Paulo, Brazil
\end{abstract}

Editor-in-Chief: Alexandre Rasi Aoki

Associate Editor: Fábio André dos Santos

Received: 2020.12.20; Accepted: 2021.05.12.

*Correspondence: amanda.mizukami@hemocentro.fmrp.usp.br; Tel.: +55-16-988212580 (A.M.).

\section{HIGHLIGHTS}

- Adaptation of HEK-293T cells to suspension and serum-free conditions was performed.

- During the whole process, kinetic and metabolic parameters were evaluated.

- HEK-293T adaptation is an important step for GMP-compliant biopharmaceutical production.

Abstract: Human Embryonic Kidney 293T cells (HEK-293T) are the most common host for viral vector production and are also widely employed for recombinant protein production. These cells are typically cultured in monolayer (adherent culture) using culture medium containing fetal bovine serum (FBS), which impairs batch-to-batch reproducibility and scale-up. The adaptation of adherent cell culture to suspension culture in chemically defined serum-free culture medium is an attractive approach for large-scale bioprocess implementation while aiming for a Good Manufacturing Practice (GMP) compliant production process. Therefore, in the present study, our goal was to adapt HEK-293T cells to serum-free suspension culture conditions and evaluate the feasibility of adapted cells to be transfected using different plasmid vectors for recombinant protein production. Firstly, the cells were efficiently adapted to serum-free conditions by sequential adaptation (FBS-containing medium weaning). During the whole process, parameters such as cell growth, viability and doubling time were evaluated and compared to the control (adherent serumsupplemented HEK-293T cell culture). Afterwards, these cells were adapted to suspension culture by using Erlenmeyer flasks in an orbital shaker platform, being able to achieve meaningful cell density with high viability. Adapted cells presented a transfection efficiency of approximately $50 \%$ for all vector constructs used (1054-GFP, Factor-VIII and Factor-IX). Overall, it was possible to successfully adapt HEK-293T cells to suspension and serum-free conditions, which represents an important step towards the development of a 
scalable and GMP-compliant production process. In addition, adapted cells efficiently expressed the different transgene tested, opening up possibilities for its use in recombinant protein production.

Keywords: serum-free media; suspension culture; HEK-293 T cells; adaptation process; recombinant protein.

\section{INTRODUCTION}

Biopharmaceuticals are biotechnological products used for therapeutic and diagnostic applications. Viral vectors and recombinant proteins represent the majority of biopharmaceutical products, providing a promising solution for the treatment of several diseases. Mammalian cells are the dominant platform used for biopharmaceutical production [1], for both clinical and research purposes, being responsible for more than $50 \%$ of therapeutic proteins approved on the market [2]. In this context, an appropriate choice of expression system and the optimization of culture methods are essential to enable rapid development and production of a product with high quality and productivity.

The Human Embryonic Kidney 293T (HEK-293T) cell line is widely used for the production of recombinant proteins and lentiviral vectors, since it is easy to transfect and can be adapted to serum-free suspension culture [3,4]. It was developed from the HEK-293 cell line with the expression of a mutant SV40 large $T$ antigen [5]. These cells possess the important characteristics of higher cell proliferation and transfection efficiency when compared to other cell lines. The presence of the SV40 antigen is also an advantage, since it enables greater vector production [6].

HEK-293T cells are typically cultivated in static cultures using culture medium supplemented with fetal bovine serum (FBS). This type of culture represents two main disadvantages: the need for a larger superficial area to enable cell growth, and the presence of FBS, which may present batch-to-batch variability and carries risks such as xenoimmunization and transmission of known and unknown pathogens. The serum-free suspension adaptation process is a viable option to overcome these limitations, and could represent an increase in terms of cell density, without the need to increase superficial area, while also favoring scale-up [7]. Several articles have demonstrated the potential of culturing HEK-293T cells in serum-free conditions in order to improve the production of biopharmaceutical products. Swiech and coauthors employed the use of a commercial suspension cell line (HEK293SF-3F6) for an efficient high-yield-rFVIII production [8]. By using HEK-293 suspension adapted cell line and an optimized culture medium devoid of animal-derived components, an increase of Virus-like particles (VLPs) was achieved, being a promise protocol for VLP production for new vaccine strategies [9]. Another interesting work showed the production of high titers of infectious influenza viruses using HEK-293 cells grown in suspension in serum-free culture medium. The authors also scale-up the production using a $3 \mathrm{~L}$ bioreactor, representing a suitable system for industrial manufacturing of influenza vaccines [10].

Thus, the aim of the present work was to adapt the human cell line HEK-293T to serum-free suspension conditions and evaluate the feasibility of adapted cells to be transfected, providing a potential scalable and GMP-compliant platform for the production of recombinant proteins for cellular therapy purposes.

\section{MATERIAL AND METHODS}

\section{Cell culture}

HEK-293T cell line (ATCC CRL-3216 ${ }^{\mathrm{TM}}$ ) was cultured in T-flasks $\left(25 \mathrm{~cm}^{2}\right)$ using Dulbecco's Modified Eagle's Medium (DMEM) (Invitrogen, Grand Island, NY) supplemented with 10\% (v/v) of Fetal Bovine Serum (FBS) (HyClone ${ }^{\mathrm{TM}}$, GE Healthcare). The flasks were maintained in an incubator with a $5 \% \mathrm{CO}_{2}$ humidified atmosphere, at $37^{\circ} \mathrm{C}$. In each passage, cells were detached using Tryple Express (Gibco, Grand Island, NY) when confluency reached $70 \%-90 \%$. The serum-free culture medium used during the adaptation process was FreeStyle 293 Expression Medium (FS, Invitrogen, Grand Island, NY) supplemented with 1\% InsulinTransferrin-Selenium (ITS) (Invitrogen, Grand Island, NY) and 10\% Cell Boost 6 (Thermo Scientific, South Logan, UT). Viability and cell density were determined by the exclusion method using $0.4 \%$ Trypan Blue solution (Invitrogen, Grand Island, NY) in a Neubauer chamber under phase contrast microscopy. 


\section{Serum-free Suspension Adaptation}

The adherent culture was adapted to serum-free conditions through sequential adaptation, by progressive passages into mixtures of FBS-containing medium and serum-free medium (SFM) until serumfree conditions were completely reached. This process commenced with a $0 \%$ SFM and was gradually increased to $25 \%, 50 \%, 75 \%, 87.5 \%, 95 \%$ until reaching $100 \%$ of serum-free conditions. Cell passages were performed every 2-5 days, during an exponential growth phase with high viability (at least $90 \%$ ). A minimum of two passages were performed for each condition.

For suspension culture adaptation, the cells were transferred to a 125-mL Erlenmeyer flask, with a working volume of $20 \mathrm{~mL}$ and an initial cell density of $3 \times 10^{5} \mathrm{cell} / \mathrm{mL}$. Cell culture was maintained in an orbital platform shaker at 150rpm.

The doubling time was calculated at each passage by using the equation: DT= $\mathrm{x} \log 2 /[\log (\mathrm{N} / \mathrm{No})]$; where $t$ represents the period of time between passages; $\mathrm{N}$ represents the final amount of cells; and No represents the initial amount of cells.

\section{Cryopreservation and Thawing}

Adherent serum-supplemented HEK-293T cells were cryopreserved by using standard freezing medium containing 90\% FBS (HyClone ${ }^{\mathrm{TM}}$, GE Healthcare) and 10\% DMSO (Sigma-Aldrich, St. Louis, MO) at a density of $1 \times 10^{7}$ cells $/ \mathrm{mL}$. Cryopreservation of SFM cultured cells was performed by using a solution composed of $50 \%$ HyCryo (Thermo Scientific, South Logan, UT) and $50 \%$ of conditioned medium at a density of $6 \times 10^{6}$ cells/mL [11]. Cells were first placed into a cryodevice (Mr. Froosty ${ }^{\mathrm{TM}}$ Freezing Container, Thermo Scientific, South Logan, UT) at $-80^{\circ} \mathrm{C}$ for at least 24 hours and then transferred to liquid nitrogen.

The vials were rapidly thawed in a $37^{\circ} \mathrm{C}$ water bath, resuspended and seeded in their respective culture medium. Cells adapted to suspension culture were maintained for 24 hours in a $75 \mathrm{~cm}^{2}$ static flask with 10 $\mathrm{mL}$ of culture medium to minimize spinning stress.

\section{Metabolite Analysis}

Supernatant samples were collected throughout the experiments and kept frozen at $-20^{\circ} \mathrm{C}$ until use. The concentration of metabolites (glucose and lactate) was measured by using a 2700 YSI Biochemical Analyzer (Yellow Springs Instruments, Yellow Springs, $\mathrm{OH}$ ). For this, $25 \mu \mathrm{L}$ of samples were analyzed in the equipment (duplicate).

\section{Characterization of cell growth kinetic}

For the adherent serum-supplemented cells, the experiment was performed in a 24-well plate for 8 days. An initial cell density of $7 \times 10^{3}$ cells $/ \mathrm{mL}$ was plated in a working volume of $1 \mathrm{~mL}$ of DMEM $+10 \% \mathrm{FBS}$ in each well (duplicate). Every $24 \mathrm{~h}$, cells were trypsinized and counted. Supernatant was collected for further metabolic analyses.

For the suspension adapted cells, $125 \mathrm{~mL}$ Erlenmeyer flasks were seeded with $3 \times 10^{5} \mathrm{cells} / \mathrm{mL}$, with a working volume of $20 \mathrm{~mL}$ of FreeStyle $293^{\mathrm{TM}}+10 \%$ CellBoost and maintained in a constant agitation of $150 \mathrm{rpm}$ for 8 days. Every 24h, $1 \mathrm{~mL}$ of the culture was removed and centrifuged, the supernatants were collected for metabolic analyses and the pellets were resuspended for cell count. Three independent experiments were performed $(n=3)$.

\section{Transient transfection}

24 hours before transient transfection, $1 \times 10^{6} \mathrm{cells} / \mathrm{mL}$ were inoculated in an Erlenmeyer flask with $20 \mathrm{~mL}$ of culture medium. The day after, $2 \times 10^{6} \mathrm{cells} / \mathrm{mL}$ were inoculated in a Corning ${ }^{\circledR}$ mini bioreactor tube with a final volume of $5 \mathrm{~mL}$ FreeStyle ${ }^{\mathrm{TM}} 293$ Expression Medium (Gibco). Both conditions were maintained at $37^{\circ} \mathrm{C}$ with constant stirring at $180 \mathrm{rpm}$ and $5 \% \mathrm{CO}_{2}$. Three different plasmid vectors were used to evaluate the transfection capacity of HEK293T adapted to serum-free suspension conditions: 1054-GFP (8700 bp), Factor VIII-GFP (14708 bp) and Factor IX-GFP (10124 bp). The total amount of DNA used was $1 \mu \mathrm{g} / 10^{6}$ cells and the transfection reagent PEIpro ${ }^{\circledR}$ was added at a 3:1 (DNA:PEI) ratio. Cell growth and viability were evaluated every 24 hours and determined by the exclusion method using $0.4 \%$ Trypan Blue solution (Invitrogen, Grand Island, NY) in a Neubauer chamber under phase contrast microscopy. Transfection efficiency was determined by a flow cytometric analysis of GFP-positive cells after 24 and 48 hours. A minimum of 10000 
events were collected for each sample and the CellQuest ${ }^{\mathrm{TM}}$ software (Becton Dickinson, San Jose, CA) was used for acquisition and analysis. Three independent experiments were performed $(n=3)$ for each vector.

\section{RESULTS}

\section{Adherent serum-supplemented HEK-293T cell culture: cell growth and metabolism}

Kinetic and metabolic characterization was first performed on HEK-293T cell line cultured under adherent serum-supplemented conditions in T-flasks for 8 days. As can be seen in Figure 1A, an intense cell growth was observed, achieving a maximum cell density of $4.9( \pm 1.1) \times 10^{5}$ cells $/ \mathrm{mL}$ at day 8 , representing a foldincrease of $70( \pm 22)$. Exponential growth phase was determined between days 2 and $5\left(u_{\max }=0.82 d^{-1}, R^{2}=\right.$ 0.95). Cell viability remained above $80 \%$ during the entire period of culture.

The concentration of glucose and lactate was measured throughout cultivation (Figure 1B). In this experiment, no culture medium change was performed (batch mode), and for this reason the concentration of glucose gradually decreased, reaching a minimum value of $2.7( \pm 0.02) \mathrm{g} / \mathrm{L}$. Lactate, a by-product of glucose metabolism, showed an increase in the concentration during cultivation, reaching the maximum value of $2.32( \pm 0.01) \mathrm{g} / \mathrm{L}$, which does not represent an inhibitory concentration for cell growth (generally for mammalian cells, lactate is considered inhibitory in concentrations above $3.56 \mathrm{~g} / \mathrm{L}$ [12]) (Figure 1B).

A

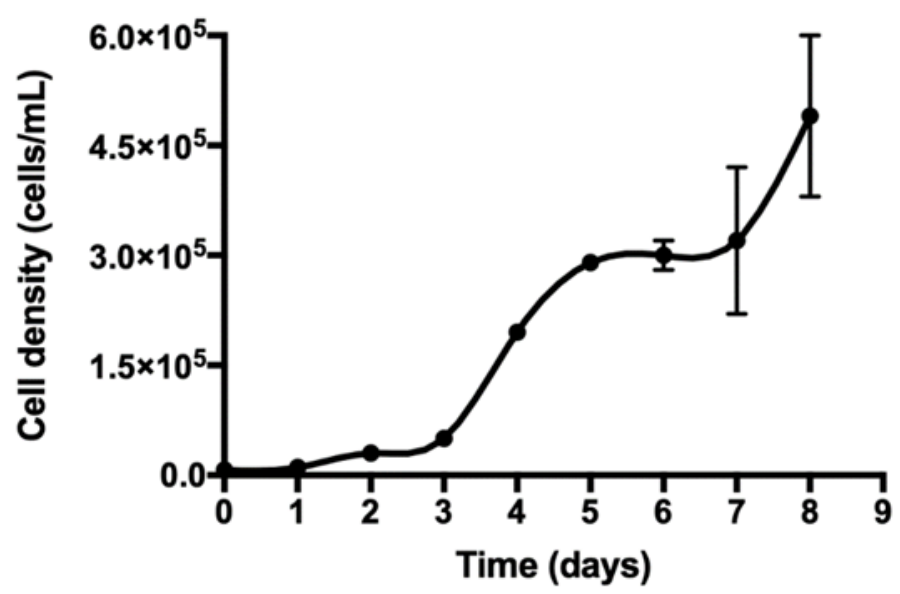

B $\rightarrow$ Glucose

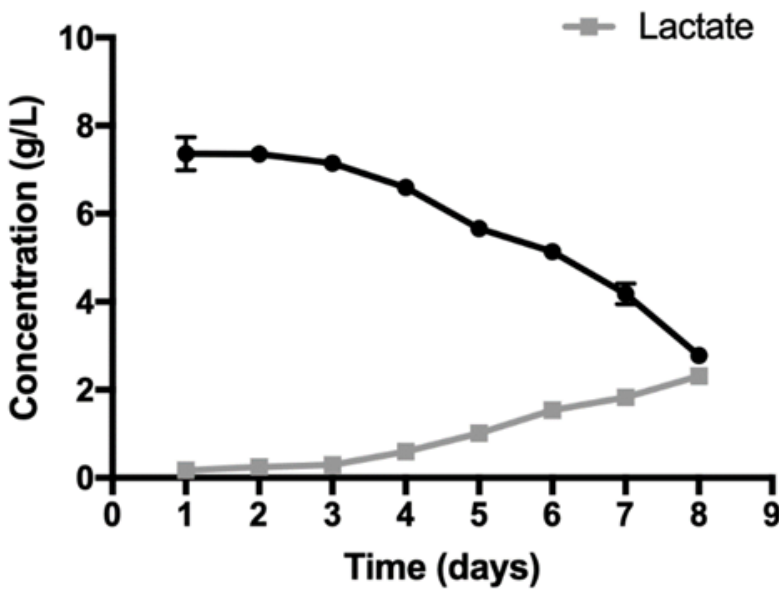

Figure 1. (A) Cell growth kinetic and (B) Glucose and lactate profile of adherent serum-supplemented HEK-293T cells cultured in a 24-well plate with an initial cell density of $7 \times 10^{3}$ cells $/ \mathrm{mL}$ for 8 days ( $\mathrm{n}=2$, two independent experiments).

\section{HEK-293T: Serum-Free medium adaptation}

Cell viability was measured during the whole process of HEK-293T cell adaptation. As described in the material and methods section, the gradual serum reduction was performed when cell viability was above $90 \%$, signaling that the cells could be adapted to the new culture medium formulation. Analyzing Figure 2 , it is possible to observe that for the majority of conditions, the cells presented low viability in the first passage after medium change, while recovering in the subsequent cell passages (above $85 \%$ ). It is important to highlight that the cells were cultured for at least 2 passages in the appropriate culture medium mixture. When the condition of $12.5 \%$ serum-containing medium (SCM) $+87.5 \%$ SFM was reached, SFM (FreeStyle) was supplemented with 1\% ITS (Invitrogen, Grand Island, NY) and $10 \%$ Cell Boost 6 (Thermo Scientific, South Logan, UT) to prevent the decrease in cell viability due to the lack of serum and to improve cell growth $[7,11]$. After the adaptation process was completed, the supplement ITS was removed and cells presented high viability after several passages (data not shown).

Figure $2 \mathrm{~F}$ shows the complete adaptation of HEK-293T cells in SFM conditions, sustaining a high cell viability $(83.4 \% \pm 0.1)$. 

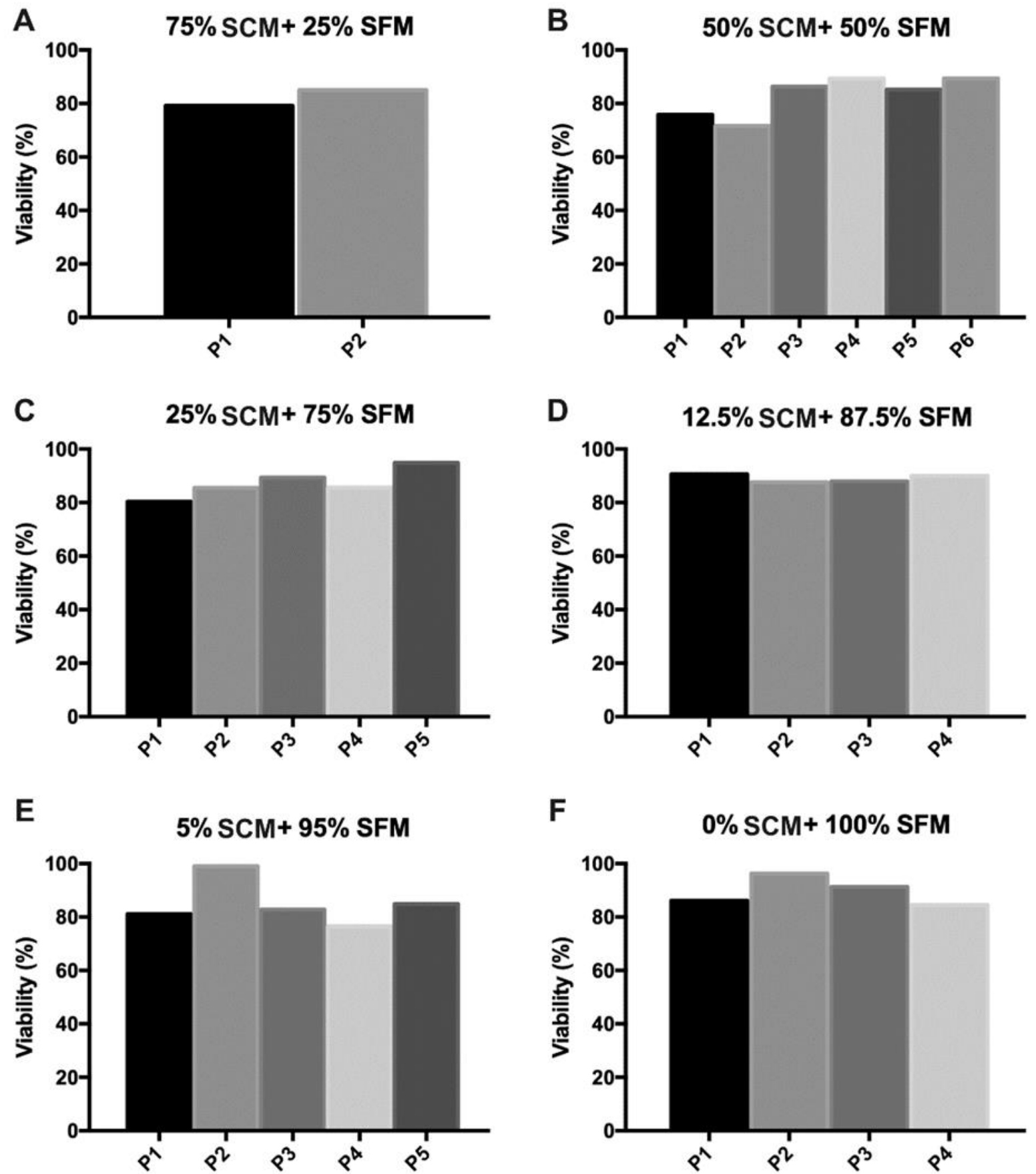

Figure 2. Cell viability during serum-free medium adaptation of HEK-293T cells. (A) $75 \% \mathrm{SCM}+25 \% \mathrm{SFM}$; (B) $50 \% S C M+50 \% S F M ; \quad$ (C) $25 \% S C M+75 \% S F M ; \quad$ (D) $12.5 \% S C M+87.5 \% S F M ; \quad$ (E) $5 \% S C M+95 \% S F M$ and (F) $0 \%$ SCM+100\%SFM. Different passages were performed for each condition.

Doubling time (DT) is an important parameter that acts as an indicator of the cell adaptation in the culture condition. For this reason, an average DT (total doublings divided by culture time) was calculated during each step of the adaptation process. As seen in Figure 3, it was possible to observe a slight increase of DT at the end of the serum-free adaptation. The average doubling time of the adapted cells (100\% SFM) was 24.3 $( \pm 12)$ hours, which is very similar to adherent cells $(19.6( \pm 0.5)$ hours). 


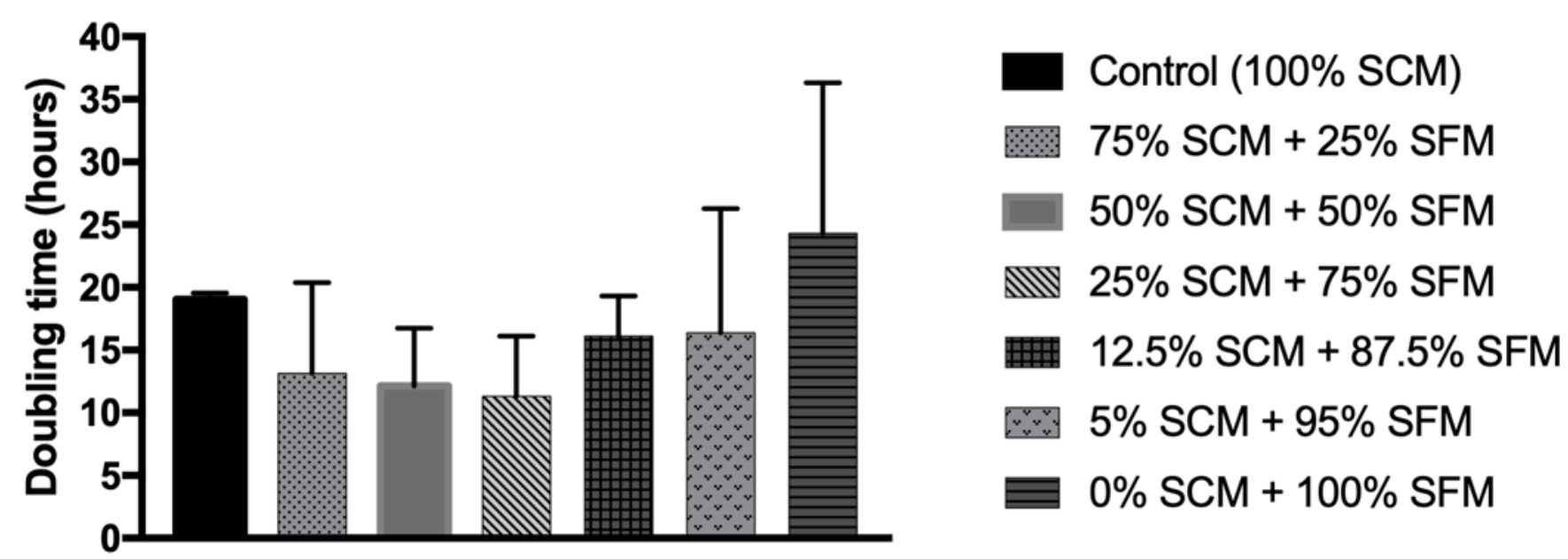

Figure 3. Average doubling time (DT) calculated for each stage of HEK-293T cell adaptation. Different passages were performed for each condition.

\section{HEK-293T: Suspension culture cell adaptation}

In order to adapt the cells to suspension conditions, HEK-293T cells previously adapted to serum-free conditions under static conditions were inoculated at $3 \times 10^{5} \mathrm{cells} / \mathrm{mL}$ into a $125 \mathrm{~mL}$ Erlenmeyer flask with 20 $\mathrm{mL}$ of working volume, stirring at $150 \mathrm{rpm}$. After full suspension adaptation, cell kinetics were followed for 8 days ( $n=4$, four independent experiments) (Figure $4 A$ ).

As can be seen in Figure $4 \mathrm{~A}$, maximum growth was obtained at day 7 , achieving $1.1( \pm 0.16) \times 10^{7}$ viable cells $/ \mathrm{mL}$. The exponential growth phase was calculated between days 2 and $6\left(u_{\max }=0.82 \mathrm{~d}^{-1}, \mathrm{R}^{2}=0.97\right)$. The cell death observed after day 7 was likely due to depletion of glucose (batch mode), since the maximum concentration of lactate reached $(3.01( \pm 0.07) \mathrm{g} / \mathrm{L})$ was not a growth inhibiting concentration [12] (Figure 4B).

Adapted cells consumed glucose, decreasing the concentration of this nutrient in the culture medium. The lowest concentration of glucose was $0.52( \pm 0.5) \mathrm{g} / \mathrm{L}$ at day 7 , coinciding with the highest viable cell concentration attained. Lactate concentration increased as a consequence of glucose consumption, also reaching its peak at day 7 .

A

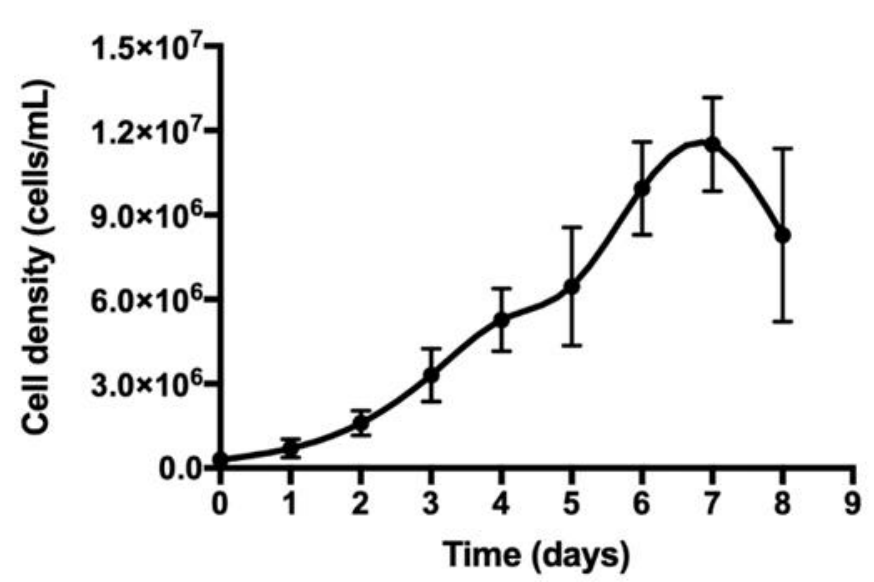

B

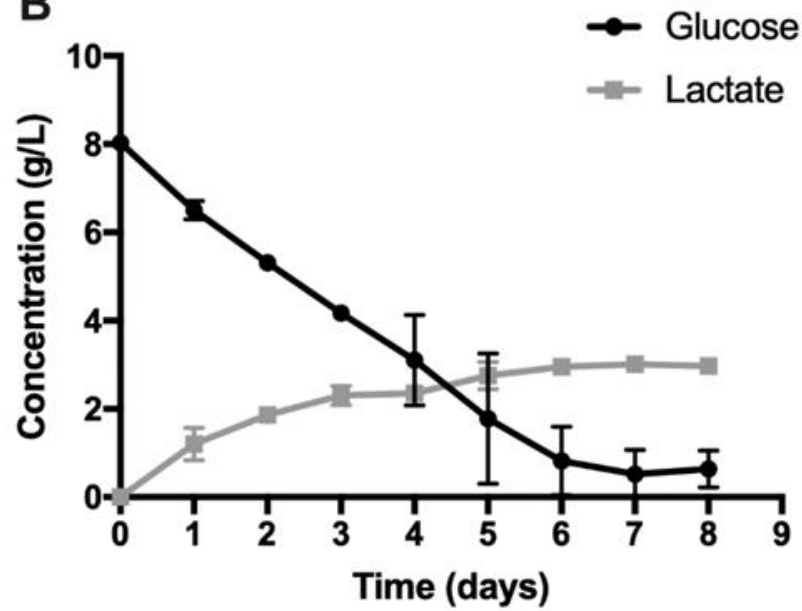

Figure 4. (A) Cell growth kinetic and (B) Glucose and lactate profile of suspension and serum-free adapted HEK-293T cells in a $125 \mathrm{~mL}$ Erlenmeyer flask for 8 days, with a seeding cell density of $3 \times 10^{5} \mathrm{cells} / \mathrm{mL}(n=4$, four independent experiments).

The morphology of the HEK-293T cell line before and after the adaptation process is shown in Figure 5. It is possible to see how the cell morphology changed from a spread (Figure 5A) to a rounded cell morphology, with a clear tendency to form aggregates (Figure 5B). 
A

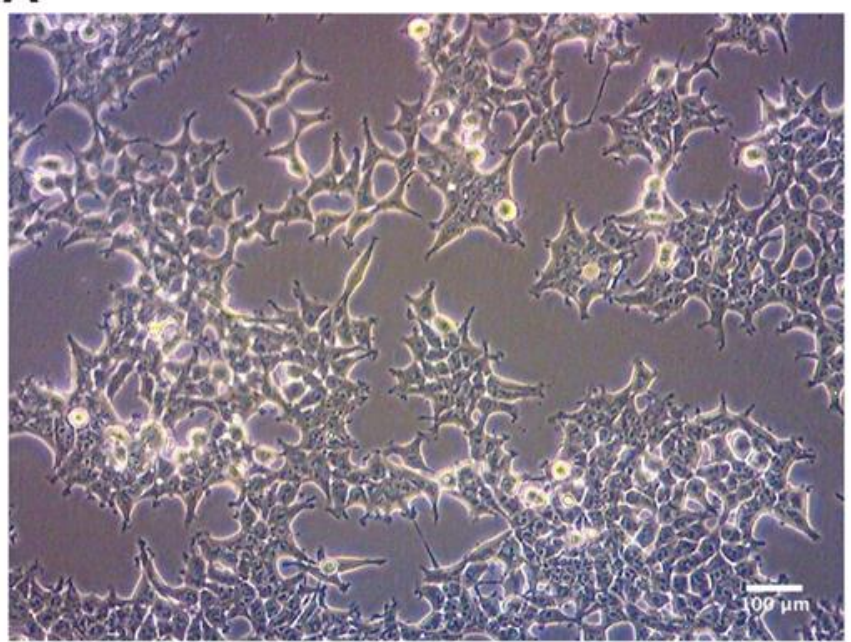

B

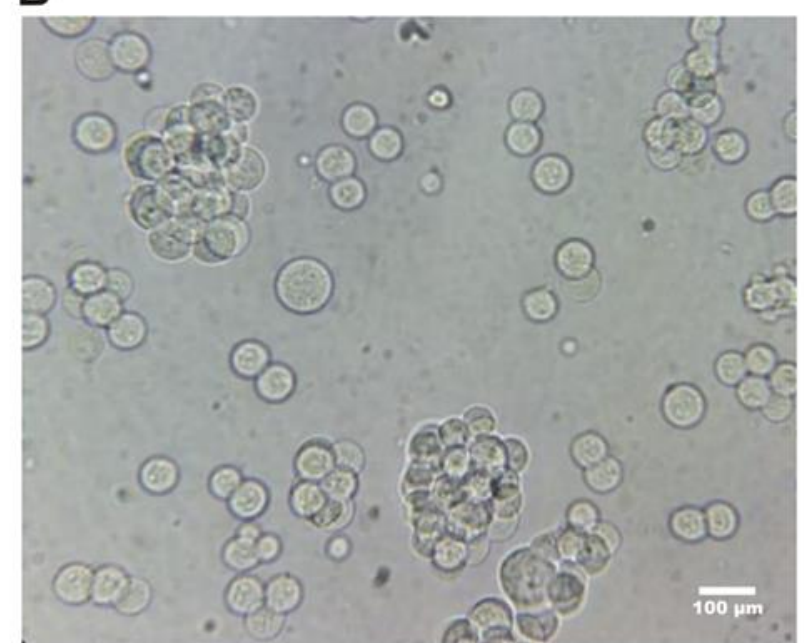

Figure 5. Images of HEK-293T cells using optical microscopy (A) before and (B) after serum-free suspension adaptation process. Magnification: 10x.

\section{Transient transfection and efficiency}

Three different plasmid vectors were used in order to assess the ability of adapted cells to be transfected. Cell growth was monitored from day 0 to 72 hours after transient transfection (Figure 6A). The expression of GFP-positive cells was analyzed by flow cytometry 24- and 48-hours post-transfection to assess efficiency. A maximum cell density of $3.5\left( \pm 0.79 \times 10^{6}\right) \mathrm{cells} / \mathrm{mL}$ and $3.7\left( \pm 1.1 \times 10^{6}\right)$ cells $/ \mathrm{mL}$ was reached 72 and 48 hours after transfection for 1054-GFP and Factor VIII-GFP vectors, respectively. $4.6\left( \pm 0.53 \times 10^{6}\right) \mathrm{cells} / \mathrm{mL}$ was attained after 72 hours for Factor IX-GFP vector (Figure 6A). The viability remained higher than $75 \%$ for all conditions (data not shown).

Figure 6B shows the percentage of cells that expressed GFP analyzed by flow cytometry for 1054-GFP, Factor VIII-GFP and Factor IX-GFP, respectively. It was possible to observe that transfection efficiencies were above $50 \%$ for all conditions after 48 hours. 

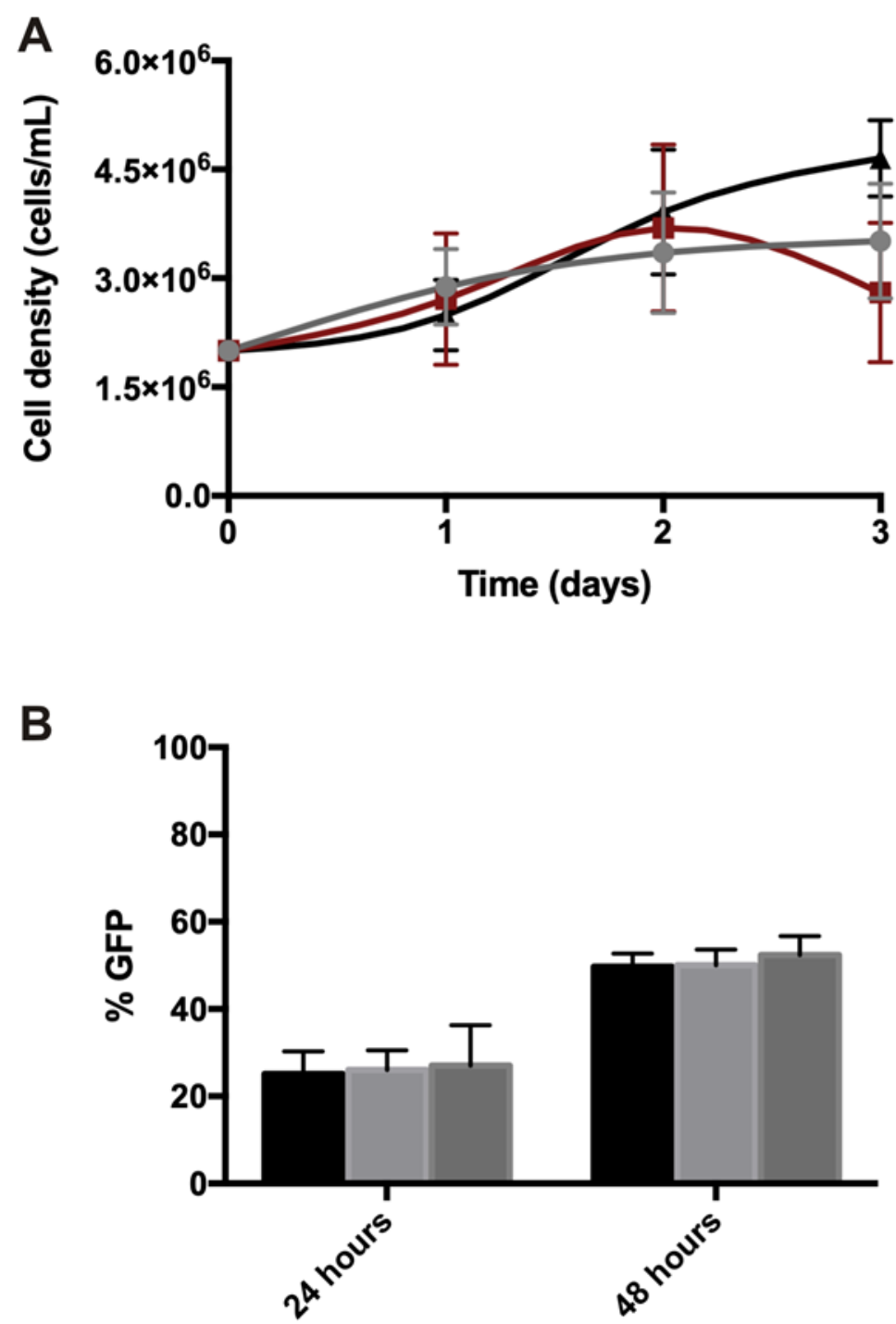

1054-GFP vector Factor VIII-GFP vector Factor IX-GFP vector

Figure 6. (A) Cell growth kinetic after transient transfection and (B) GFP positive cells analyzed by flow cytometry for 1054-GFP, Factor VIII-GFP and Factor IX-GFP vectors.

\section{DISCUSSION}

The adaptation of cell lines to suspension growth is desired as biopharmaceutical industry is always concerned with large-scale processes to increase productivity while decreasing costs. Furthermore, biological products with lower costs could be more accessible to Low and Middle Income Countries (LMICs) [13]. Due to welfare concerns and several technical and economic drawbacks regarding the use of fetal bovine serum (FBS) for cell culture supplementation, it is also recommended the FBS replacement to chemically defined serum-free medium. Thus, the use of serum-free culture medium will result in safer products, contribute to animal protection arguments regarding the harvest and collection of FBS from bovine fetuses and better availability of culture media components with transparent and traceable composition [14].

In the present work, we adapted HEK-293T cells to serum-free medium by progressively reducing the amount of FBS, while monitoring cell growth and viability up to the complete elimination of FBS. When comparing the present results to those in the literature for adapted and commercial cell lines, it is clear that our adaptation protocol was efficient, and is comparable with theirs $[8,15]$. The doubling time of the adapted cells $(100 \%$ SFM) was $24.3( \pm 12)$ hours, which is very similar to adherent cells $(19.6( \pm 0.5)$ hours) and to those described in the literature for adapted HEK-293T cells (23.4 \pm 2.7 hours) [16]. Importantly, cell viability remained above $80 \%$ in all conditions tested.

Another key feature that could be addressed is the optimization of the feeding regimen. Kinetic characterization for adherent serum-supplemented and SFM conditions was performed in a batch culture mode, ie, without culture medium change. Comparing the metabolism of the adapted cells to the serumsupplemented cells, it was possible to observe a faster consumption of glucose, correlating with the higher 
cell concentration obtained in the suspension culture. In addition, for adapted cells, lactate did not reach the inhibitory levels for cell growth, (generally for mammalian cells, lactate is considered inhibitory in concentrations above $3.56 \mathrm{~g} / \mathrm{L}$ [12]), but glucose reached near exhaustion levels after day 7 . This nutrient limitation could be the explanation for the observed cell death after this period. To further maximize cell expansion in this system, $50 \%$ of culture medium exchange could be implemented, in order to replenish nutrients and growth factors and dilute toxic by-products, while minimizing the removal of autocrine factors that promote cell growth.

The adapted cells reached $1.1( \pm 0.16) \times 10^{7}$ viable cells $/ \mathrm{mL}$, while maintaining a high cell viability, which also represents a density greater than those described in literature for adapted HEK293-T cells $\left(3 \times 10^{6}\right.$ cells $/ \mathrm{mL}$ [16]). The future implementation of bioreactor culture will potentially increase the cell density due to tight controls of culture parameters and consequently improve the quality and productivity of the desired therapeutic product [17].

Regarding transfection experiments, similar results were found in the literature using transient plasmid transfection of HEK293 cells and PEI reagent. Ehrhadt and colleagues (2006) achieved transfection efficiency of 55.9\% using HEK 293 suspension cells and GFP vector construct [17]. Another study showed 75\% of transgene expression varying the concentration of PEI [18]. No differences or correlations between the value of GFP-positive cells and the size of the vector were observed in this work (1054-GFP: $8700 \mathrm{bp}$, Factor VIIIGFP: 14708 bp and Factor IX-GFP: 10124 bp). Fuenmayor and coauthors also revealed that transfection efficiency is not dependent in plasmid size or vector type, but on DNA and PEI quantities. Optimizing DNA and $P E I$ ratios could greatly influence the process and significantly increase transfection efficiency [19].

Our intention was only to verify if the adapted cells for serum-free and suspension conditions were able to incorporate the transgene using our standard protocol. Further experiments need to be performed to optimize the protocol established and quantify the recombinant protein production. However, this first effort paves the way for future implementation of a horizontal platform for biopharmaceutical and lentiviral vector production, expanding our possibilities for a robust, scalable and lower cost production platform.

\section{CONCLUSION}

In the present work, HEK-293T cell line was successfully adapted to a serum-free suspension culture, while being able to maintain the main characteristics (growth pattern, viability and doubling time). Adapted cells were able to efficiently express the different vectors tested. Adaptation of HEK-293T in suspension and under serum-free conditions represents an important step in the development of scalable and cost-effective biopharmaceutical production in compliance with GMP guidelines.

Funding: This research was funded by FAPESP (2017/21737-2), CTC Center for Cell-based Therapies (FAPESP 2013/08135-2) and National Institute of Science and Technology in Stem Cell and Cell Therapy (CNPq 573754-2008-0 and FAPESP 2008/578773).

Conflicts of Interest: The authors declare no conflict of interest.

\section{REFERENCES}

1. Berlec A, Štrukelj B. Current state and recent advances in biopharmaceutical production in Escherichia coli, yeasts and mammalian cells. J Ind Microbiol Biotechnol. 2013; 40(3-4):257-74.

2. Zhu J. Mammalian cell protein expression for biopharmaceutical production. Biotechnol Adv. 2012; 30(5):1158-70.

3. Dumont JA, Liu T, Low SC, Zhang X, Kamphaus G, Sakorafas P, et al. Prolonged activity of a recombinant factor VIII-Fc fusion protein in hemophilia A mice and dogs. Blood. 2012;119(13):3024-30.

4. Fischer S, Charara N, Gerber A, Wolfel J, Schiedner G, Voedisch B, et al. Transient recombinant protein expression in a human amniocyte cell line: The CAP-T® cell system. Biotechnol Bioeng. 2012;109(9):2250-61.

5. DuBridge R, Tang P, Hsia H, Leong P, Miller J, Calos M. Analysis of mutation in human cells by using an EpsteinBarr virus shuttle system. Mol Cell Biol. 1987;7(1):379-87.

6. Merten O-W, Charrier S, Laroudie N, Fauchille S, Dugué C, Jenny C, et al. Large-Scale Manufacture and Characterization of a Lentiviral Vector Produced for Clinical Ex Vivo Gene Therapy Application. Hum Gene Ther. $2011 ; 22(3): 343-56$.

7. Sinacore M, Drapeau D, Adamson S. Adaptation of Mammalian Cells to Growth in Serum-Free Media. Mol Biotechnol. 2000;15(3):249-58.

8. Swiech K, Kamen A, Ansorge S, Durocher Y, Picanço-Castro V, Russo-Carbolante EMS, et al. Transient transfection of serum-free suspension HEK 293 cell culture for efficient production of human rFVIII. BMC Biotechnol. 2011;11:114. 
9. Cervera L, Gutiérrez-Granados S, Martínez M, Blanco J, Gòdia F, Segura MM. Generation of HIV-1 Gag VLPs by transient transfection of HEK 293 suspension cell cultures using an optimized animal-derived component free medium. J Biotechnol. 2013; 166: 152-65.

10. Le Ru A, Jacob D, Transfiguracion J, Ansorge S, Henry O, Kamen AA. Scalable production of influenza virus in HEK-293 cells for efficient vaccine manufacturing. Vaccine. 2010; 28:3661-71.

11. Biaggio R, Abreu-Neto M, Covas D, Swiech K. Serum-free suspension culturing of human cells: adaptation, growth, and cryopreservation. Bioprocess Biosyst Eng. 2015; 38(8):1495-07.

12. Altamirano C, Gòdia F, Cairó J. Metabolismo de células de mamíferos cultivadas in vitro. In: Moraes AM, Augusto EFP, Castilho LR, editors. Tecnologia de cultivo de células animais: de biofármacos a terapia gênica. São Paulo: Roca; 2008.

13. Bauler M, Roberts JK, Wu C-C, Fan B, Ferrara F, Yip BH, et al. Production of Lentiviral Vectors Using Suspension Cells Grown in Serum-free Media. Methods Clin Dev. 2019; 17:58-68.

14. Gstraunthaler G, Lindl T, van der Valk J. A plea to reduce or replace fetal bovine serum in cell culture media. Cytotechnology. 2013; 65(5): 791-93.

15. Ansorge S, Lanthier S, Transfiguracion J, Durocher Y, Henry O, Kamen, A. Development of a scalable process for high-yield lentiviral vector production by transient transfection of HEK293 suspension cultures. J Gene Med. 2009; 11(10):868-76.

16. Adam E, Sarrazin S, Landolfi C, Motte V, Lortat-Jacob H, Lassale P, et al. Efficient long-term and high-yielded production of a recombinant proteoglycan in eukaryotic HEK293 cells using a membrane-based bioreactor. Biochem Biophys Res Commun. 2008; 369(2):297-302.

17. Ehrhardt C, Schmolke M, Matzke A, Knoblauch A, Will C, Wixler V, et al. Polyethylenimine, a cost-effective transfection reagent. Signal Transd. 2006; (6):179-84.

18. Durocher $\mathrm{Y}$, Perret $\mathrm{S}$, Kamen A. High-level and high-throughput recombinant protein production by transient transfection of suspension-growing human 293-EBNA1 cells. Nucleic Acids Res. 2002; (30):2-e9.

19. Fuenmayor J, Cervera L, Gutiérrez-Granados S, Gòdia F. Transient gene expression optimization and expression vector comparison to improve HIV-1 VLP production in HEK293 cell lines. Appl Microbiol Biotechnol. 2018; (102):165-74.

2021 by the authors. Submitted for possible open access publication under the terms and conditions of the Creative Commons Attribution (CC BY NC) license (https://creativecommons.org/licenses/by-nc/4.0/). 